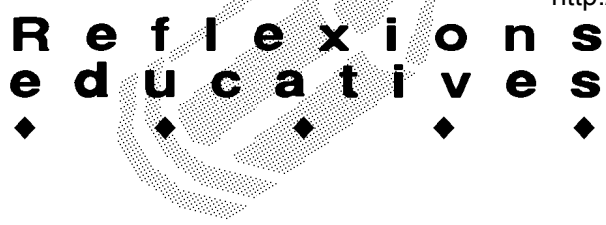

\title{
ALGUNS REPTES ACTUALS EN LA FUNCIÓ DEL MESTRE
}

\author{
Jacky Verrier. Àrea de Didàctica de la Llengua i la Literatura
}

\section{Dos models de formació en paral-lel}

Quan el pedagog P. Meirieu, en el seu llibre: Aprendre...sí, però com?(1992) diu que "Tots podem aprendre sempre i a tot arreu, que l'aprenentatge no es limita als llocs assignats" posa de manifest un fet que podem resumir així: Enfront de l'aprenentatge al'escola -formació intramurs- hi ha l'aprenentatge extraescolar -formació extramurs-. L'entorn i la societat han creat les seves pròpies fonts de difusió del coneixement, que poden portar, a curt o a llarg termini, a privar l'escola del monopoli de la difusió del coneixement, de la formació i del saber i, a més a més, dels seus rituals tradicionals en la transmissió del saber (grup classe, lentitud necessària, metòdica i gradual de la presentació dels continguts, complicitat del grup basada en la convivència diària...).

D'aquí es desprenen dues observacions: el mestre, entès com a difusor del saber, ha d'acceptar que amb aquests nous difusors l'accés al coneixement ha obert noves vies extraescolars, i d'aquí en endavant el coneixement no és exclusivament propietat seva. Les tecnologies que sorgeixen cada dia imposen nous tipus d'adquisició i nous comportaments. Els espais, els instruments d'informació s'han multiplicat i diversificat -cibercafès, biblioteques i diaris informatitzats, el Louvre en CD ROM...-, i han donat lloc a una nova organització del temps -no cal que ens la portin, sinó que és aquí, múltiple i variada, que es pot buscar fent zapping- i, d'altra banda, una mercantilització dels continguts. Només cal fer un cop d'ull al mercat de la informació per adonar-se que és a l'abast de tothom -autoaprenentatge de les llengües estrangeres a través de tot tipus d'instruments informàtics, amb el premi d'un professor a casa, enciclopèdies en CD ROM, publicacions de vulgarització, del tipus Muy Interesante, o bé enciclopèdies que es poden comprar còmodament a terminis $\mathrm{i}$ que donen a qualsevol de nosaltres (o ens ho fan creure) el dret a la cultura a un preu raonable-. L'editorial Océano ha publicat una enciclopèdia dels coneixements en 16 volums per a alumnes de primària $i$ secundària, en la qual es diu: "La nostra enciclopèdia dels coneixements és el sistema d'estudi més eficaç per a l'alumne. Adaptada a la LOGSE, tracta les matèries que aquesta llei ha introduït en el sistema educatiu. Totalment al dia, conté els textos més moderns per a respondre a les necessitats de l'alumne d'avui. Creada per estudiar, aquesta obra ofereix centenars d'exercicis d'autoavaluació, amb les seves solucions corresponents perquè l'alumne pugui avaluar i controlar el grau d'assimilació dels seus coneixements". D'altra banda, en una enquesta sobre els manuals escolars, publicada en la revista francesa Le Nouvel Observateur (setembre, 1996), el mateix Meirieu afirmava: "La trilogia sagrada d'una escola, basada en l'aliança entre l'alumne, el professor i el llibre, és morta". I la revista afegia: "No és estrany, doncs, que els nostres alumnes abandonin els llibres de text per acudir a devorar les guies de preparació per als exàmens que proposa el mercat extraescolar". Però abandonar el llibre de text implica al mateix temps treure al professor una bona part de la seva legitimitat com a docent, per donar-la a unes fonts d'informació que no pertanyen a l'escola, i a més a més, suposa treure també una part de la responsabilitat, de la llibertat i dels ritmes d'aprenentatge que tenia el docent per transferir-los a l'alumne.

D'aquí que ens puguem preguntar com la institució escolar podrà assimilar i administrar aquesta nova situació. Si les propostes d'aprenentatge fora de l'escola són múltiples i variades, responent així a unes necessitats específiques, una altra cosa és l'aprenentatge emmarcat dins d'una política institucional determinada que té un "públic" sense necesitats immediates, unes pautes d'aprenentatge constants i un professorat poc preparat per respondre a unes demandes socials variables i canviants.

\section{De la formació unitària cap a la competència indivi- dualitzada}

La formació del ciutadà, entès com a ésser social i treballador dins del compromís unitari, ha deixat pas a la formació de l'individu com a ésser únic que té la seva competència i autonomia personal. Per a la institució escolar, aquesta situació implica el pas d'una formació globalitzada cap a una formació personalitzada, i la desaparició progressiva dels nivells, objectius i metodologies unitaris. El problema que es planteja aleshores és el de la correspondència entre els sistemes d'ensenyament $i$ les demandes socioculturals. D'una banda, l'obertura de l'escola cap al fet social ha provocat un replantejament del principi d'educació formal, que l'obliga a renunciar implícitament a l'estat de jerarquia, de control i de 


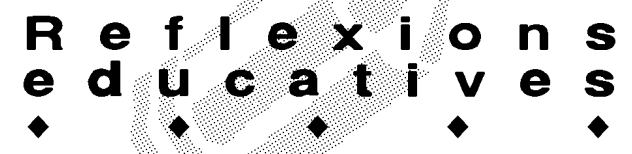

planificació dels currículums unificats, i al mateix temps, a introduir uns sabers fonamentats ja no sobre principis científics absoluts, sinó sobre una concepció pluralista i un relativisme cultural, provocats per l'heterogeneïtat de les formes de vida i la rapidesa dels canvis tecnològics que s'oposen al pes de les ciències clàssiques. D'altra banda, les demandes dels adolescents han introduït a la classe un nou clima i noves relacions entre els professors, les matèries i ells. En aquest sentit, el sociòleg A. Touraine pregunta en el seu llibre Critica de la modernitat (1992) si es pot "parlar de l'èxit de l'escola quan està dividida en dues: d'una banda, els mestres, que es veuen obligats a transmetre coneixements acceptats per la seva utilitat social; de l'altra, una joventut que viu en un món cultural completament dissociat de l'ensenyament". Dins de la classe, això suposa el pas del domini de la matèria al domini de la metodologia, que és degut, en part, al desinterès per la reflexió i el saber històric en profit del saber funcional, operatiu i de les activitats de producció.

L'escola es troba en una situació delicada. Considerada durant molt temps com el bastió de la raó, oferia un ensenyament basat en la matèria, i tenia com a objectiu la formació intel-lectual. Tanmateix, sota la pressió del pragmatisme, ha passat de la supremacia dels continguts a la del "saber fer", i aquesta transformació l'ha portat cap a una nova concepció de la seva funció, on l'èxit és el resultat d'estratègies més que les conseqüències de la racionalitat tradicional. Per tant, no interessa tant l'adquisició com la seva manipulació.

Tota aquesta situació ens ha conduït cap a un replantejament de les nocions de cultura i de saber, i al mateix temps, d'autoritat, de moral, de creences, on conviuen zones tan diverses com les comunicacions d'alta i baixa densitat, l'estabilitat i la inestabilitat de les normes, la durada de la història col-lectiva i el caràcter efímer de l'experiència perso- nal, la recerca del plaer immediat, la cultura del supermercat $\mathrm{i}$ la del museu, que representen tantes altres ofertes quotidianes, a les quals podem afegir la barreja entre el real i el virtual.

\section{Conclusions}

Les ambigüitats anteriors ens porten a concloure que l'ensenyament ha de redefinir la seva posició a partir de dos punts:

a) La relegitimació del paper del mestre, que per raons òbvies desconfia moltes vegades dels instruments de difusió de la cultura de massa, i ha de lluitar contra les fonts externes d'aprenentatge. En aquest sentit, ha de buscar en el seu espai professional les raons, les motivacions i els fonaments de la seva identitat com a educador.

b) La relegitimació de la llengua, que ha de ser un espai compartit entre el saber fer i el saber. Aquest espai hauria d'integrar la reflexió sobre la llengua, el pes i el paper del lèxic i el contrast entre les llengües i les cultures, sobretot en un món que viu sota la influència del llenguatge sintètic, de les barreges culturals i religioses, i immers dins d'una redefinició de les identitats nacionals.

I dins la classe, on es proposa i utilitza tot un material extralingüístic -aspectes lúdics, icònics, etc.- per estimular la curiositat de l'alumne i del mestre, creiem que és dins de la llengua i del mestre que es troben els fonaments de l'esdevenidor de l'ensenyament de les llengües, pròpies o estrangeres. Per tant, creiem finalment que el mestre ha d'alliberar-se d'uns principis d'ensenyament que no són seus, redefinir el seu estatut, reconduir les seves reflexions, els seus objectius propis i els continguts d'aprenentatge en funció de la seva situació específica.

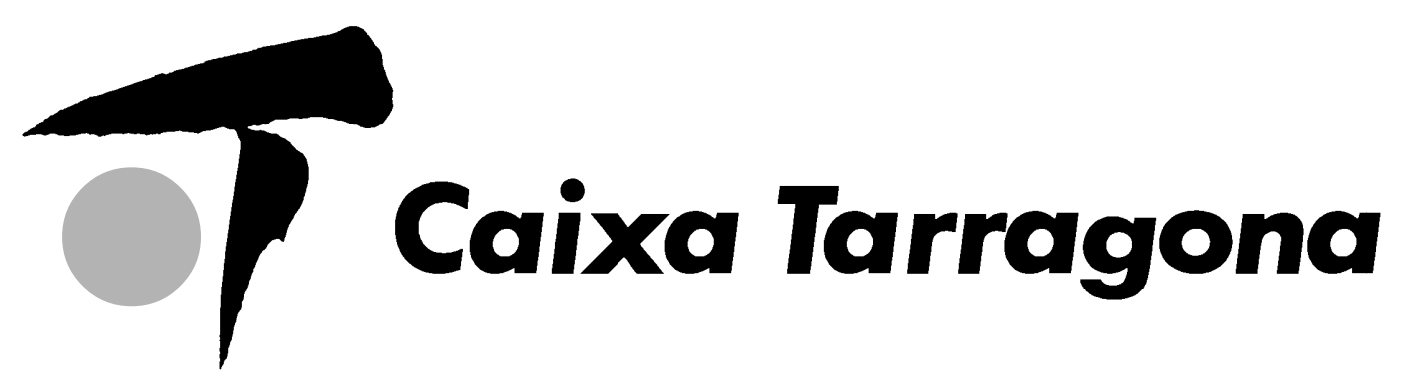

